\title{
Association between fear of missing out in social media and problematic internet use in university students
}

\author{
Hatice Aygar ${ }^{1 \oplus}$, Saniye Goktas ${ }^{1 \oplus}$, Sevil Akbulut Zencirci ${ }^{1 \oplus}$, Melike Alaiye ${ }^{2 \oplus}$, Muhammed Fatih Onsuz ${ }^{1}$, \\ Selma Metintas ${ }^{10}$
}

${ }^{1}$ Eskisehir Osmangazi University, Faculty of Medicine, Department of Public Health, Eskisehir - Turkey

${ }^{2}$ Eskişehir Osmangazi University, Faculty of Medicine, Department of Internal Medicine, Eskisehir - Turkey

\begin{abstract}
Objective: The aim of this study was to determine the association between the fear of missing out (FoMO) in social media and problematic Internet use in university students and to evaluate the related sociodemographic characteristics.

Method: This was a cross-sectional study conducted with university students at Eskisehir Osmangazi University in 2016. In this study, 463 students were reached by multistage sampling. Problematic Internet use was measured by the Problematic Internet Usage Scale (PIUS) and FoMO in social media was measured by the Fear of Missing Out Scale (FoMOs). Mann Whitney U test, Kruskal-Wallis test (Bonferroni correction), Spearman correlation analysis, multiple linear regression, and multiple logistic regression analyses were used.

Results: The students' mean age (SD) was 21.0 (1.7) years, 54.9\% (254) were male, and 91.4\% of the students had Internet access at their accommodation; 74.5\% were using the Internet for social sharing. The mean scores (SD) for PIUS and FoMOs were 65.19 (22.34) and 22.37 (7.41), respectively. Male students and students using the Internet for social sharing and reporting spending more than four hours per day on the Internet and the smartphone took higher mean scores from PIUS and FoMOs. Gender, Internet use for social sharing, and daily duration of smartphone use were found to be variables affecting the FoMOs score. After adjusting for affective factors, a positive relation was found between the FoMO and problematic Internet use.

Conclusion: In the study, the use of Internet for social sharing, time per day spent with the smartphone, and problematic Internet use were found to be factors affecting the FoMO. Increasing problematic Internet use and FoMO in university students are significant forms of addiction requiring preventive measures.
\end{abstract}

Keywords: Fear of missing out in social media, problematic internet use, university students

\section{INTRODUCTION}

With the rapid penetration of the Internet into everyday life, the fear of missing out (FoMO) has emerged in social media as a common problem. The
FoMO on social networks and the fear of not being able to keep track of their development is expressed as an addiction type that can cause individuals to spend a considerable amount of time logged into social network accounts (1). Virtual forums used for

How to cite this article: Aygar H, Goktas S, Akbulut Zencirci S, Alaiye M, Onsuz MF, Metintas S.Association between fear of missing out in social media and problematic internet use in university students. Dusunen Adam The Journal of Psychiatry and Neurological Sciences 2019;32:302-308.

Correspondence: Hatice Aygar, Department of Public Health, Faculty of Medicine, Eskisehir Osmangazi University, Meselik Campus, Eskisehir - Turkey Phone: +90 22223929 79/4517 E-mail: haticeaygar1990@gmail.com

Received: July 02, 2019; Revised: August 20, 2019; Accepted: October 16, 2019 
communication are becoming increasingly prevalent in people's everyday lives, with increasing frequency especially in youths and young adults (2). The number of persons using Facebook, the most widely used social media platform in the world today, is estimated to be around 2 billion (3). FoMO is the fear that others are making experiences that the affected persons desire for themselves, wanting to be connected to what other people are doing. Individuals who suffer from the FoMO want to know what others are doing, follow their updates, and want their own updates to be followed (1). They report a serious discomfort when they stay away from social networks and when they miss new updates, and at times they feel lonely when they are away from those networks (4).

Healthy Internet use is the use of the Internet for a specific purpose, at an appropriate time, without any cognitive or behavioral discomfort (5). Problematic Internet use can be defined as the failure to control the continuous use of the Internet because of problems such as individuals' family and work experiences (6). As the Internet is universal, easily accessible, and contains stimuli that can appeal to different tastes, social media and similar environments that allow for easy communication with other people without any responsibility while hiding one's identity and personal attributes, it entails a high risk for problematic use and dependence (7). The Survey of Household Use of Information Technologies 2016 (8) found that Internet use is most common in the age group 16-24 and among more highly educated individuals. It has been emphasized that problematic Internet use is a kind of behavioral addiction and should be evaluated specifically in adolescents and young adults who are said to be at high risk for this affliction $(9,10)$.

In a systematic review published in 2014 , problematic Internet use has been reported to be influenced by Internet use in the presence of other accompanying symptoms or illnesses (11). Widespread Internet use in daily life has led to an increase in the use of social media. Inevitably, the FoMO in social media will increase Internet usage time. However, both problematic Internet use and the FoMO in social media may cause negative effects on mental health, especially in the young age group, though there is not enough information available about the association between problematic Internet use and the FoMO in social media. Based on this observation, the aim of the study was to determine the relationship between problematic Internet use and FoMO in social media among university students and to evaluate the sociodemographic characteristics affecting them.

\section{METHOD}

This is a cross-sectional study among university students at Eskisehir Osmangazi University carried out in 2016. Administrative and ethics permissions were received allowing the work to be done. For the study, the minimum sample size was calculated to be 384 people with a $20 \%$ frequency of problematic Internet use, $4 \%$ variance level, and $95 \%$ confidence level. The study group was selected by a multistage sampling method, stratified according to the faculties and departments of the university. The study group was chosen according to the proportion of the number of students in each stratum. Classes to be selected from the faculties were determined randomly. The students who were present in class were told the purpose of the study, and individuals who agreed to participate in the study were asked to read and respond to the questionnaire. It took about 15 minutes for students to complete the survey under surveillance.

\section{Measures}

The questionnaire used in the study consisted of three parts. The first part inquired about sociodemographic characteristics, the second part consisted of variables related to the internet use and "Problematic Internet Usage Scale" that could be related to the use of the Internet, and the third part was the "Fear of Missing out in Social Media scale" in social media.

Problematic Internet Usage Scale (PIUS): The PIUS, a measure of 33 items, was developed by Ceyhan et al. (12). The instrument consists of five questions scored on a Likert-type scale from "completely fit" to "not at all suitable." The possible total score varies between 33 and 165. A greater score indicates a more unhealthy Internet use with negative effects on daily life.

Fear of Missing Out Scale (FoMOS): The FoMOs was developed by Przyblski et al. (1) and the validityreliability study of the Turkish version resulted in a measure of 10 items created by Gokler et al. (13). The items on the instrument are scored on a five-point Likert-type scale between " $1=$ not true at all" and " $5=$ extremely right." The possible total score varies between 10 and 50, and there is no cutoff score. With an increase of the score, it is accepted that behavior becomes riskier. Both of the scales include participants' own assessments. 


\section{Statistical Analysis}

The data obtained in the study were computerized and evaluated using SPSS version 15.0. The scores from PIUS and FoMOS were evaluated regarding normal distribution, and the Kolmogorov-Smirnov normal distribution test and graphs were used to show that the scores taken from both scales were normally distributed. Mann-Whitney U and Kruskal-Wallis tests, (Bonferroni correction), Spearman correlation analysis, multiple linear regression, and multiple logistic regression analyses were used. The logarithms of the scores were taken to apply linear regression. A multivariate linear regression model was performed to determine the variables affecting the FoMOS scores. The FoMOS score was obtained as a dependent variable in the model. In order to determine the relation between FoMOS and PIUS, hierarchical linear regression analysis was performed. Of the univariate variables (gender, age group, socioeconomic level, accommodation, Internet access at the accommodation, Internet use for social sharing, time spent on the Internet per day, time spent on the smartphone per day), those that were identified as significant $(\mathrm{p}<0.05)$ were included in the model. In this context, firstly, a two-stage model was performed with sociodemographic characteristics and then Internet usage characteristics. Finally, the PIUS score was added.

\section{RESULTS}

Of the 463 students who constituted the study group, $54.9 \%$ (254) were male and $45.1 \%$ (209) were female. The age of the study group ranged from 18 to 24 years and the mean (SD) was 21.0 (1.7) years. The distribution of the study group according to sociodemographic and Internet habit characteristics is given in Table 1.

Of the participants, $91.4 \%$ had access to the Internet in the place where they lived, and three quarters (74.5\%) were using the Internet for social sharing purposes. One third of the students $(33.3 \%)$ spent more than 4 hours per day on the Internet, and another $34.6 \%$ spent more than 4 hours daily on the smartphone.

The PIUS score ranged from 33.0 to 165.0 , with a mean (SD) of 65.19 (22.34). The FoMOS score ranged from 10.0 to 50.0 with a mean (SD) of 22.37 (7.41). Both PIUS and FoMOS scores were higher in males. There was no relation between age group, socioeconomic level, accommodation, and Internet access at the accommodation and scores obtained from PIUS and
Table 1: Distribution of students according to sociodemographic and Internet usage characteristics

Sociodemographic and Internet usage characteristics

n $\%$

Gender

Female

$209 \quad 45.1$

Male

254

54.9

Age group (years)

18-20 years $207 \quad 44.7$

21-24 years $256 \quad 55.3$

Socioeconomic level

$\begin{array}{lcc}\text { Low } & 24 & 5.2 \\ \text { Moderate } & 393 & 84.9 \\ \text { High } & 46 & 9.9\end{array}$

\section{Accommodation}

Home $\quad 301 \quad 65.0$

Dormitory

$162 \quad 35.0$

Internet access at the accommodation

$\begin{array}{lll}\text { Yes } & 40 & 8.6\end{array}$

$\begin{array}{lll}\text { No } & 423 & 91.4\end{array}$

Internet use for social sharing

$\begin{array}{lll}\text { Yes } & 118 & 25.5\end{array}$

No $\quad 345 \quad 74.5$

Time per day spent on the Internet

$\begin{array}{lll}1-4 \text { hours } & 309 & 66.7\end{array}$

More than 4 hours $\quad 154 \quad 33.3$

Time per day spent with smartphone

$\begin{array}{lll}1-4 \text { hours } & 303 & 65.4 \\ \text { More than 4 hours } & 160 & 34.6\end{array}$

FoMOS. With Internet use for social sharing, the scores obtained from PIUS and FoMOS were higher in those who reported spending more than 4 hours on the Internet or smartphone daily. The distribution of the students' PIUS and FoMOS scores in the study group according to sociodemographic characteristics is presented in Table 2.

There was a moderate positive correlation between the FoMOS and PIUS scores in the study group $(\mathrm{r}=0.422, \mathrm{p}<0.001)$.

Table 3 shows the multiple-analysis model of the variables that affect students' FoMOS scores.

In order to determine the relationship between the FoMO in social media scale and problematic Internet use, hierarchical linear regression analysis was performed to check the effect of other factors. After adjusting for gender $(\beta=-0.020)$, use of Internet for social sharing purposes $(\beta=0.035)$ and the time per day 
Table 2: Comparison of students' PIUS and FoMOS scores according to sociodemographic and Internet usage characteristics

\begin{tabular}{|c|c|c|c|c|}
\hline & $\begin{array}{l}\text { PIUS median } \\
\text { (min.-max.) }\end{array}$ & $\mathbf{p}$ & $\begin{array}{l}\text { FoMOs median } \\
\text { (min.-max.) }\end{array}$ & $\mathbf{p}$ \\
\hline \multicolumn{5}{|l|}{ Gender } \\
\hline Female & $57(33-133)$ & $\leq 0.001$ & $21(10-47)$ & 0.021 \\
\hline Male & $64(35-165)$ & & $23(10-50)$ & \\
\hline \multicolumn{5}{|l|}{ Age group (years) } \\
\hline $18-20$ years & $61(36-165)$ & 0.347 & $22(10-47)$ & 0.242 \\
\hline 21-24 years & $60(33-165)$ & & $22(10-50)$ & \\
\hline \multicolumn{5}{|l|}{ Socioeconomic level } \\
\hline Low & $70(42-128)$ & 0.135 & $23(11-39)$ & 0.520 \\
\hline Moderate & $59(33-165)$ & & $22(10-50)$ & \\
\hline High & $61(35-133)$ & & $21(10-40)$ & \\
\hline \multicolumn{5}{|l|}{ Accommodation } \\
\hline Home & $61(33-165)$ & 0.235 & $22(10-50)$ & 0.912 \\
\hline Dormitory & $59(36-165)$ & & $22(10-47)$ & \\
\hline \multicolumn{5}{|c|}{ Internet access at the accommodation } \\
\hline Yes & $62(40-124)$ & 0.254 & $23(10-40)$ & 0.476 \\
\hline No & $60(33-165)$ & & $22(10-50)$ & \\
\hline \multicolumn{5}{|c|}{ Internet use for social sharing } \\
\hline Yes & $55(35-165)$ & 0.005 & $20.5(10-50)$ & 0.005 \\
\hline No & $62(33-160)$ & & $23(10-47)$ & \\
\hline \multicolumn{5}{|c|}{ Time per day spent on the Internet } \\
\hline $1-4$ hours & $58(33-160)$ & $\leq 0.001$ & $21(10-47)$ & $\leq 0.001$ \\
\hline More than 4 hours & $65(36-165)$ & & $24(10-50)$ & \\
\hline \multicolumn{5}{|c|}{ Time per day spent with the smartphone } \\
\hline $1-4$ hours & $58(33-160)$ & 0.003 & $21(10-50)$ & $\leq 0.001$ \\
\hline More than 4 hours & $64(36-165)$ & & $24(10-47)$ & \\
\hline
\end{tabular}

PIUS: Problematic Internet Usage Scale, FoMOS: Fear of Missing out in Social Media Scale.

Table 3: Multiple analysis model of the variables that affect students' FoMOS scores

\begin{tabular}{|c|c|c|c|}
\hline Variables & $\begin{array}{c}\beta \\
(95 \% \mathrm{Cl}) \\
\end{array}$ & $\begin{array}{c}\beta \\
(95 \% \mathrm{Cl}) \\
\end{array}$ & $\begin{array}{c}\beta \\
(95 \% \mathrm{Cl}) \\
\end{array}$ \\
\hline \multirow[t]{2}{*}{ Gender } & $-0.032^{* *}$ & $-0.035^{* *}$ & -0.020 \\
\hline & $(-0.059$ to -0.004$)$ & $(-0.062$ to -0.008$)$ & $(-0.046$ to 0.005$)$ \\
\hline \multirow[t]{2}{*}{ Internet use for social sharing } & & $0.045^{* *}$ & $0.035^{* *}$ \\
\hline & & (0.014 to 0.075$)$ & (0.006 to 0.064$)$ \\
\hline \multirow[t]{2}{*}{ Time per day spent on the Internet } & & 0.023 & \\
\hline & & $(-0.009$ to 0.055$)$ & \\
\hline \multirow[t]{2}{*}{ Time per day spent with a smartphone } & & $0.051^{* *}$ & $0.047^{* * *}$ \\
\hline & & (0.019 to 0.082$)$ & 0.020 to 0.076 \\
\hline \multirow[t]{2}{*}{ PIUS total score } & & & $0.361^{* * *}$ \\
\hline & & & (0.266 to 0.4552$)$ \\
\hline $\mathbf{R}^{2}$ & 0.015 & 0.072 & 0.170 \\
\hline $\mathbf{F}$ & $6.870^{* *}$ & $8.950^{* * *}$ & $23.467^{* * *}$ \\
\hline
\end{tabular}


Table 4: Results of multiple logistic regression analysis to determine the characteristics of students in the study group who scored higher than the mean score on both PIUS and FoMOS

\begin{tabular}{lcc} 
& $\begin{array}{c}\text { OR } \\
(95 \% \text { CI) }\end{array}$ & p \\
\hline Gender & 1.561 & 0.046 \\
& $(1.008-2.418)$ & \\
$\begin{array}{l}\text { Using the Internet for } \\
\text { social sharing }\end{array}$ & 2.397 & 0.002 \\
$\begin{array}{l}\text { Time per day spent on } \\
\text { the Internet }\end{array}$ & 1.614 & \\
$\begin{array}{l}\text { Time per day spent with } \\
\text { a smartphone }\end{array}$ & $(0.991-2.628)$ & \\
& 1.663 & 0.055 \\
& $(1.020-2.712)$ & \\
\hline
\end{tabular}

PIUS: Problematic Internet Usage Scale, FoMOS: Fear of Missing Out Scale, $\mathrm{Cl}$ : Confidence intervals.

spent with a smartphone $(\beta=0.047)$, the last model showed that the score obtained from FoMOS still had a positive relation with scores from PIUS $(\beta=0.361)$.

We found that $38.9 \%$ of the study group scored higher on PIUS and $46.7 \%$ on FoMOS compared to the mean score of the study group, and 123 (26.6\%) of the students in the study group received higher scores than the mean score from both PIUS and FoMOS. The results of multiple logistic regression analyzes performed to determine the characteristics of students who reached higher scores than the mean score from both PIUS and FoMOS are given Table 4.

\section{DISCUSSION}

Co-occurrence of problematic Internet use and FoMO is common among young people. Most studies reported that problematic Internet use is a serious public health problem (14). FoMO in social media is a newer type of addiction and has been studied less. FoMO in social media is expected to have a high prevalence, as Internet access at the accommodation is available to $91.4 \%$ of students, and $74.5 \%$ of them use the Internet for social sharing. The more widespread use of social networking sites has increased interactivity among young people, as well as the urge to controlling their online presence intensively and share frequent updates about their own situation.

In the study group, it was determined that the FoMO and problematic Internet use changed in similar ways according to sociodemographic and
Internet use characteristics. There was a moderately positive relationship between problematic Internet use and FoMO. It has been reported that Internet addiction is associated with the FoMO (15). Another study done among students suggests that the use of Facebook as a social media tool contributes to the severity of symptoms associated with Internet addiction (16). It was found that in the study group; males, students using the internet for social sharing and students spending four or more hours on the internet and smartphone scored higher from PIUS and FoMOS.

Studies have reported that male students show higher degrees of Internet addiction than women $(17,18)$. However, some studies have reported that FoMOS scores do not differ by gender $(19,20)$. In our study, the age profile of the study group and differences in the methods used may have had an impact. It has been reported that gender differences may change the purpose of Internet use as well as Internet dependency: according to on study, male high school students use the Internet mostly for online games and female students for social interaction (18). There are also studies suggesting that women use the Internet more for online communication $(18,21)$. Individuals who use social networking sites more often may experience more FoMO (22).

Students spending more than 4 hours per day on the Internet were found to have highly problematic Internet use and greater FoMO. There are publications reporting a relationship between problematic Internet use and the duration of Internet use $(22,23)$. The definition of problematic Internet use also includes the failure to control the use of the Internet, causing an increase in the time spent on the Internet. It has been reported that students having many social network accounts and staying updated on the newest events, access to the Internet more frequently and for longer periods of time and have more FoMO (13).

Smartphones allow accessing online social networking sites from everywhere and at any time, providing access to online games and mobile Internet applications, which increases the time spent on social networking sites and therefore the duration of Internet use.

The use of smartphones may be related to problematic Internet use; it has been reported that "phubbing," dealing with the smartphone and escaping from interpersonal communication which is associated with the FoMO, is positively related to Internet addiction $(19,24)$. It has been reported that 
requests of users to access the Internet and Internet applications whenever they want increases problematic Internet use, possibly at the same time affecting smart phone dependency (2). A recent study reported that FoMO is an indicator for smartphone dependency (19).

Among the limitations of this study, we need to mention that its cross-sectional approach does not allow to explain cause-effect relationships; as the sample of the study consists of university students of the same age group recruited at only one university, its generalizability may be limited.

Internet use for social sharing, the time per day spent with a smartphone, and problematic Internet use were found to be factors affecting the FoMO in the study. In multivariate analysis, the factors associated with scoring above the mean on both PIUS and FoMOS were male sex, Internet use for social sharing, and mobile phone use for more than 4 hours daily. The fact that problematic Internet use and FoMO in social media are affected by similar variables can be seen as strong evidence for the relationship between them.

Increasing problematic Internet use and FoMO in university students are remarkable, constituting a type of dependency requiring precautions to be taken. Awareness towards vulnerable groups at risk should be raised in this regard. Further studies are needed to examine the effects of these addictions on mental health and public health in Turkey.

\begin{tabular}{|c|c|c|}
\hline \multicolumn{2}{|c|}{ Contribution Categories } & \multirow{2}{*}{\begin{tabular}{|l} 
Author Initials \\
H.A., S.G., S.A.Z., M.A., \\
M.F.O., S.M.
\end{tabular}} \\
\hline \multirow{3}{*}{ Category 1} & Concept/Design & \\
\hline & Data acquisition & H.A., S.G., S.A.Z., M.A. \\
\hline & Data analysis/Interpretation & H.A., S.G., S.A.Z., M.A., S.M. \\
\hline \multirow[t]{2}{*}{ Category 2} & Drafting manuscript & $\begin{array}{l}\text { H.A., S.G., S.A.Z., M.A., } \\
\text { M.F.O., S.M. }\end{array}$ \\
\hline & Critical revision of manuscript & H.A., M.F.O., S.M. \\
\hline Category 3 & Final approval and accountability & $\begin{array}{l}\text { H.A., S.G., S.A.Z., M.A., } \\
\text { M.F.O., S.M. }\end{array}$ \\
\hline \multirow{2}{*}{ Other } & Technical or material support & H.A., S.G., S.A.Z., M.A. \\
\hline & Supervision & M.F.O., S.M. \\
\hline
\end{tabular}

Ethics Committee Approval: The study was approved by the Ethics Committee of the Anadolu University.

Informed Consent: Written informed consent was obtained from the patients.

Peer-review: Externally peer-reviewed.

Conflict of Interest: The authors report no conflicts of interest.

Financial Disclosure: None declared.

\section{REFERENCES}

1. Przybylski AK, Murayama K, DeHaan CR, Gladwell V. Motivational, emotional, and behavioral correlates of fear of missing out. Comput Human Behav 2013; 29:1841-1848. [CrossRef]

2. Oberst U, Wegmann E, Stodt B, Brand M, Chamarro A. Negative consequences from heavy social networking in adolescents: the mediating role of fear of missing out. J Adolesc 2017; 55:51-60.

3. Clement J. Facebook - Statistics and Facts. Statista, 2019. https:// www.statista.com/topics/751/facebook/. Accessed October 23, 2019.

4. Dossey L. FOMO, digital dementia, and our dangerous experiment. Explore (NY) 2014; 10:69-73. [CrossRef]

5. Davis RA. A cognitive-behavioral model of pathological Internet use. Comput Human Behav 2001; 17:187-195. [CrossRef]

6. Kim HK, Davis KE. Toward a comprehensive theory of problematic Internet use: evaluating the role of self-esteem, anxiety, flow, and the self-rated importance of Internet activities. Comput Human Behav 2009; 25:490-500. [CrossRef]

7. Griffiths M. Internet gambling: issues, concerns, and recommendations. Cyberpsychol Behav 2003; 6:557-568. [CrossRef]

8. Turkish Statistical Institute. Survey of Household Use of Information Technologies, 2016., August 18, 2016. http://www. tuik.gov.tr/PreHaberBultenleri.do?id=21779 Accessed August 3, 2017.

9. Grant JE, Potenza MN, Weinstein A, Gorelick DA. Introduction to behavioral addictions. Am J Drug Alcohol Abuse 2010; 36:233-241. [CrossRef]

10. Holden C. Behavioral addictions debut in proposed DSM-V. Science 2010; 327:935. [CrossRef]

11. Kuss DJ, Griffiths MD, Karilla L, Billieux J. Internet addiction: a systematic review of epidemiological research for the last decade. Curr Pharm Des 2014; 20:4026-4052. [CrossRef]

12. Ceyhan E, Ceyhan AA, Gurcan A. The validity and reliability of the problematic Internet Usage Scale. Educational Sciences: Theory \& Practice 2007; 7:411-416.

13. Gokler ME, Aydin R, Unal E, Metintas S. Determining validity and reliability of Turkish version of Fear of Missing out Scale. Anadolu Psikiyatri Derg 2016; 17:53-59. (Turkish) [CrossRef]

14. Beranuy M, Oberst U, Carbonell X, Chamarro A. Problematic Internet and mobile phone use and clinical symptoms in college students: the role of emotional intelligence. Comput Human Behav 2009; 25:1182-1187. [CrossRef]

15. Kandell JJ. Internet addiction on campus: the vulnerability of college students. Cyberpsychol Behav 1998; 1:11-17. [CrossRef]

16. Kittinger R, Correia CJ, Irons JG. Relationship between Facebook use and problematic Internet use among college students. Cyberpsychol Behav Soc Netw 2012; 15:324-327. [CrossRef]

17. Durkee T, Kaess M, Carli V, Parzer P, Wasserman C, Floderus B, Apter A, Balazs J, Barzilay S, Bobes J, Brunner R, Corcoran P, Cosman D, Cotter P, Despalins R, Graber N, Guillemin F, Haring C, Kahn JP, Mandelli L, Marusic D, Meszaros G, Musa GJ, Postuvan V, Resch F, Saiz PA, Sisask M, Varnik A, Sarchiapone 
M, Hoven CW, Wasserman D. Prevalence of pathological internet use among adolescents in Europe: demographic and social factors. Addiction 2012; 107:2210-2222. [CrossRef]

18. Lee $\mathrm{YH}$, Ko $\mathrm{CH}$, Chou $\mathrm{C}$. Re-visiting Internet addiction among Taiwanese students: a cross-sectional comparison of students' expectations, online gaming, and online social interaction. J Abnorm Child Psychol 2015; 43:589-599. [CrossRef]

19. Chotpitayasunondh V, Douglas KM. How "phubbing” becomes the norm: the antecedents and consequences of snubbing via smartphone. Comput Human Behav 2016; 63:9-18. [CrossRef]

20. Gokler ME, Aydin R, Unal E and Metintas S. "Fear of Missing Out" in university students in western area of Turkey. Eur J Public Health 2016; 26(Suppl.1):478. [CrossRef]
21. Ang CS. Internet habit strength and online communication: exploring gender differences. Comput Human Behav 2017; 66:1-6.

22. Gezgin DM, Hamutoglu NB, Gemikonakli O, Raman I. Social networks users: fear of missing out in preservice teachers. Journal of Education and Practice 2017; 8:156-168.

23. Tahiroglu AY, Celik GG, Fettahoglu C, Yildirim V, Toros F, Avci A, Ozatalay E, Uzel M. Problematic Internet use in the psychiatric sample compared community sample. Noro Psikiyatr Ars 2010; 47:241-246. (Turkish)

24. Karadag E, Tosuntas SB, Erzen E, Duru P, Bostan N, Sahin B, Culha I, Babadag B. Determinants of phubbing, which is the sum of many virtual addictions: a structural equation model. J Behav Addict 2015; 4:60-74. [CrossRef] 